\title{
Measuring e-Learning Readiness Concept: Scale Development and Validation Using Structural Equation Modeling
}

\author{
Farid Alem ${ }^{1}$, Michel Plaisent ${ }^{2}$, Cataldo Zuccaro ${ }^{2}$, Prosper Bernard ${ }^{2}$ \\ 1 Ahuntsic College of Montreal, Montreal, Canada. \\ 2 University of Quebec in Montreal, Montreal, Canada. \\ * Corresponding author. Tel.: +1 (514) 987-3000 x 4253; email: michel.plaisent@uqam.ca \\ Manuscript submitted July 10, 2016; accepted December 23, 2016. \\ doi: 10.17706/ijeeee.2016.6.4.193-207
}

\begin{abstract}
The purpose of this paper is to develop and validate an instrument to measure the concept of e-readiness in the context of online learning environment. A rigorous method of scale development was undertaken to achieve this purpose: conceptual model development, item generation, content validation, exploratory study, and confirmatory study. The results of a study conducted in university, specializing in online education, suggest that the e-learning readiness (ELR) is a five-dimensional construct, namely Self Competence, Self-Directed Learning, Motivation, Financial, and Usefulness. Further psychometric tests show a parsimonious ELR measure with support for convergent, discriminant and predictive validities. In addition, these results show that the second-order factor model is the better fitting for the e-learning readiness construct. Based on the results, it can be concluded this instrument is useful and appropriate is assessing e-learning readiness construct. The theoretical and practical implications of the study as well as directions for future research are discussed.
\end{abstract}

Key words: E-learning readiness, reliability, scale development, second-order, validity.

\section{Introduction}

Although there are several studies focused on online teaching strategies and technological innovations, they seem to have ignored a relatively important detail regarding the readiness of students to learning [1]. Moreover, some studies have shown that most students are not prepared for the virtual learning environment. Despite the existence of literature on e-learning readiness, some authors of existing tools and others have strongly recommended in future research to proceed firstly to improve the internal and external validity of these tools, and secondly, to take into account other dimensions [1]. According to these authors, the development of an e-learning readiness instrument is highly desirable to identify risk students in the virtual learning environment. The authors add that this instrument can identify early students who have difficulties taking online courses.

It is felt that a better knowledge of e-learning and better preparation before taking online courses allow learners to be able to perform better and to continue their study with this mode of teaching. It therefore seems important that there is some assessment of the preparedness of a learner before taking online courses. This assessment allows us to indicate whether the learner is able or not to adapt to this teaching mode. 
A recent study presented the different existing tools in the context of e-learning readiness and showed that the absence of the reliability and validity of these tools is an issue at the heart of online learning [2]. However, in their study, the authors highlighted the different reasons related to the validity of these tools. Despite the importance of ELR concept, there have been no significant efforts to develop a standard instrument to measure the various dimensions of this concept.

\section{E-Learning Readiness Concept}

The concept of e-readiness is used from the 2000 and refers to the readiness of a country to adopt information and communication technologies (ICT) [3]. Thus, the term "e-readiness" is defined as the level of development at which an individual is ready to undertake learning with specific hardware [3]. According to [4], readiness for university education can be defined as the level of preparation a student needs in order to enroll and succeed, without remediation in a credit-bearing program at higher education institution. The authors define the e-learning readiness as the degree to which learners are ready to taking courses in online learning environment. Learners must have prerequisite behavioral attributes, skills and orientations that will prepare them to enroll in online courses.

The e-readiness is introduced in several areas such as e-commerce, e-government and e-business. Although there are several studies focused on teaching strategies / learning and technological innovation, they seem to have ignored the preparation of students to study in the online context. Indeed, some authors recommend that a valid e-readiness tool to be useful, reliable and improve retention rates and success of online learners [1].

In the individual context, most of the institutions and researchers highlighted the growing interest and potential of the e-readiness of learners online. Some researchers have shown that students who thrive in an online learning environment seem to have some academic preparation characteristics such as self-directed learning, self-competence, motivation, self-discipline and learning style [5]. Indeed, these authors point out that students who are successful in the online environment are those that are well prepared and ready to follow their study online and non-face, skilled in the use of technology and browsing the Internet, and able to learn autonomously.

As there is no single theory of online learning to do, we can use a combination of theories to develop our tool. Indeed, many theorists have argued, and the experience of practitioners themselves, online learning is a subset of learning in general. The choice of dimensions of the tool has been determined by two theories as Social Cognitive theory and Transactional Distance theory, and the results of the systematic review conducted by [2]. To this end, we relied on earlier studies identified in the systematic review and the theories to describe the main dimensions of e-learning readiness that are capable of measuring the level of preparedness of learners towards online learning. The authors of this paper propose ELR as being a multidimensional construct consisting of five factors.

\subsection{Self-competence}

The concept of self-competence refers to the judgment on the ability to deploy skills in the use of any computer tool, not only the acquisition of these skills [6], Some authors have stressed that it is important to have a certain level of technical computer skills before to take courses online [7]. In addition, this concept can predict whether a learner is ready or not to take online courses. The motivational strategies to predict the performance of students revealed that the self-competence is one of the best predictors of a successful learner in the learning environment online [7].

\subsection{Self-directed Learning}

The concept of self-directed learning is seen as a learning process in which learners are mainly based on 
the planning. Some researchers reported that learning requires considerably autonomy and self-direction of learning, and online students must take a great responsibility to manage and monitor their academic progress [8]. Self-directed learning plays a critical role in e-learning because the needs of the learners focus on learning management strategies. Moreover, self-directed learning has been adopted by many researchers as a theoretical framework / practice to understand the success of students in an online environment [9].

\subsection{Motivation}

In the field of education, motivation has been identified as a critical factor affecting learning [10]. It is considered as a psychological attribute that encourages students to learn. Motivation is a key factor in maintaining the satisfaction of learners in an online learning environment [11]. Moreover, according to these authors, it is important to investigate the motivation of online learners, including its antecedents and outcomes. In addition, several studies have shown that cognitive factors such as motivation contribute to the online learner success [12].

\subsection{Financial}

The financial difficulties faced by the students to continue their online courses have become an important factor. Moreover, [13] points out that money is an important factor that hinders many students not to take distance courses. In addition, [13] emphasizes that to encourage students to engage in online learning, it is necessary that their financial situation be improved. Therefore, financial support is a significant factor of success to completion or not an online course [5].

\subsection{Usefulness}

Perceived usefulness is defined as, the degree to which a person believes that using a particular system would enhance his performance at work [14]. As part of this study, perceived usefulness denotes the benefits derived from using e-learning such as saving time and money. Some authors have shown a positive relationship between technology readiness and perceived usefulness [15]. The latter argued that this related to the degree of readiness that the individual felt in using a technology. E-learning is considered as a technology that plays an important role in education.

\section{Methodology}

The methodology is based on the steps recommended by [16] for the development and validity of the instrument. This allows build a rigorous measure tools like multi-scale questionnaires. The steps are as follows: Items generation, Content validity, Pretest, Pilot test, and Final Test.

\subsection{Items Generation}

In this study, we have taken to ensure objectivity in the selection of items. For this, a few items of measurement scales from the systematic review, conducted by [2], were used and adapted to our study and others have been created. At the beginning, we have identified 44 items to assess the e-learning readiness. The eleven items of self-competence were inspired by the work of [17], and we have added other items following the rapid changes in the field of information technology (IT). Self-directed learning was captured by 14 items adapted from [18], [19], and [20]. Motivation was measured by 9 items adapted from [10] as well as from [1]. Perceived usefulness was taped by 4 items adapted from [14]. Six items of the dimension Financial are all new and developed from the review of the literature.

\subsection{Content Validity}

After generating a set of items to our questionnaire, it is recommended that evaluation by experts or judges panel [21]. The draft instrument was carried out by recruiting a panel of thirty-two (32) experts 
around the world. The panel members are university professors specializing in distance education and online learning who published in peer-reviewed journals, heads of organizations specializing in distance education and online and officials of Chairs in distance education in different countries. The anonymity of the experts is achieved via the distribution of questionnaires to avoid a direct encounter (face to face) among experts. This allows for an independence of judgments [22], thus limiting the psychological effects involved in direct social interactions as a pressure group or inhibition. Our choice is focused on the method of [23] who proposed the validity ratio content (Content validity ratio CVR) to measure the degree of agreement among experts on the relevance of the items.

Lawshe's method is to ask experts to specify individually for each item if it is 1) not relevant, 2) significant but not essential, or 3) essential. The CVR of each item obtained from the formula of Lawshe is between -1 and +1 , the positive value indicates that more than half of the experts noted that the item is essential. The experts will also be able to add items deemed essential but which were not included in the initial version of the questionnaire. They could also suggest move an item of a construct to another. All suggestions will be analyzed.

The results of this content validity showed that only 41 of the 44 proposed items are subject to a strong consensus by experts in other words are essential (CVR them is greater than 0.90). This shows that all constructs have a level of acceptable validity of content and this means that the items were representative of the construct.

\subsection{Pre-test}

This step aims to detect errors, to ensure proper understanding of the issues and fluidity of the questionnaire and evaluate the mean duration of response [24]. Specifically, 25 graduate students who were not part of the study sample had access to the online questionnaire to bring their comments and suggestions regarding the clarity of the questions, the accuracy of the terms used, identifying too complex questions, and verification of usability of the website. Overall, the items were sufficiently clear and understandable for most participants. As regards the time required to respond to the questionnaire was approximately 10 minutes. After having checked and corrected, a pilot test will be conducted in the next step to ensure that the instrument can be used properly and the responses obtained are consistent.

\subsection{Pilot Test}

The objective of the pilot test is to conduct a preliminary assessment of the metrological quality of a measuring instrument, in other words to check the reliability of the items. An online survey was conducted to test the instrument ELR. All 41 items of questionnaire are measured on Likert's seven-point scale ranging from 1 "strongly disagree" to 7 "strongly agree" with 4 as "neutral". A demographic section was also included at the end of the questionnaire. An exploratory factor analysis with oblique rotation was used to purify the instrument. This analysis was performed using SPSS V.19 software on a sample of 112 university students who have no experience in online education. The final solution identified a structure of five factors comprising 17 items as shown in Table 1 with own values greater than 1 and that explain $80.70 \%$ of the total variance. This percentage is acceptable because it is above the thresholds recommended by [25]. In addition, the maximum likelihood test was not significant $(\chi 2=77.18, \mathrm{df}=.72$, sig. $=0.346)$ which means that the model is consistent with the data. This result was obtained after the third iteration and successive elimination of items with less than 0.5 loading and which cross-loaded on two or more factors at 0.4 or higher [25].

We see through the table above, all Cronbach's alpha coefficients are greater than 0.70 . A score of a Cronbach's alpha greater than or equal to 0.7 is considered adequate to determine the reliability of the instrument and this reflects an adequate and reliable internal consistency of scales [25]. In the next step, we 
will conduct a thorough investigation of the reliability with the Jöreskog's rho and construct validity including the predictive validity of the final version of the tool.

Table 1. Factor Loading of the 17 Final Items

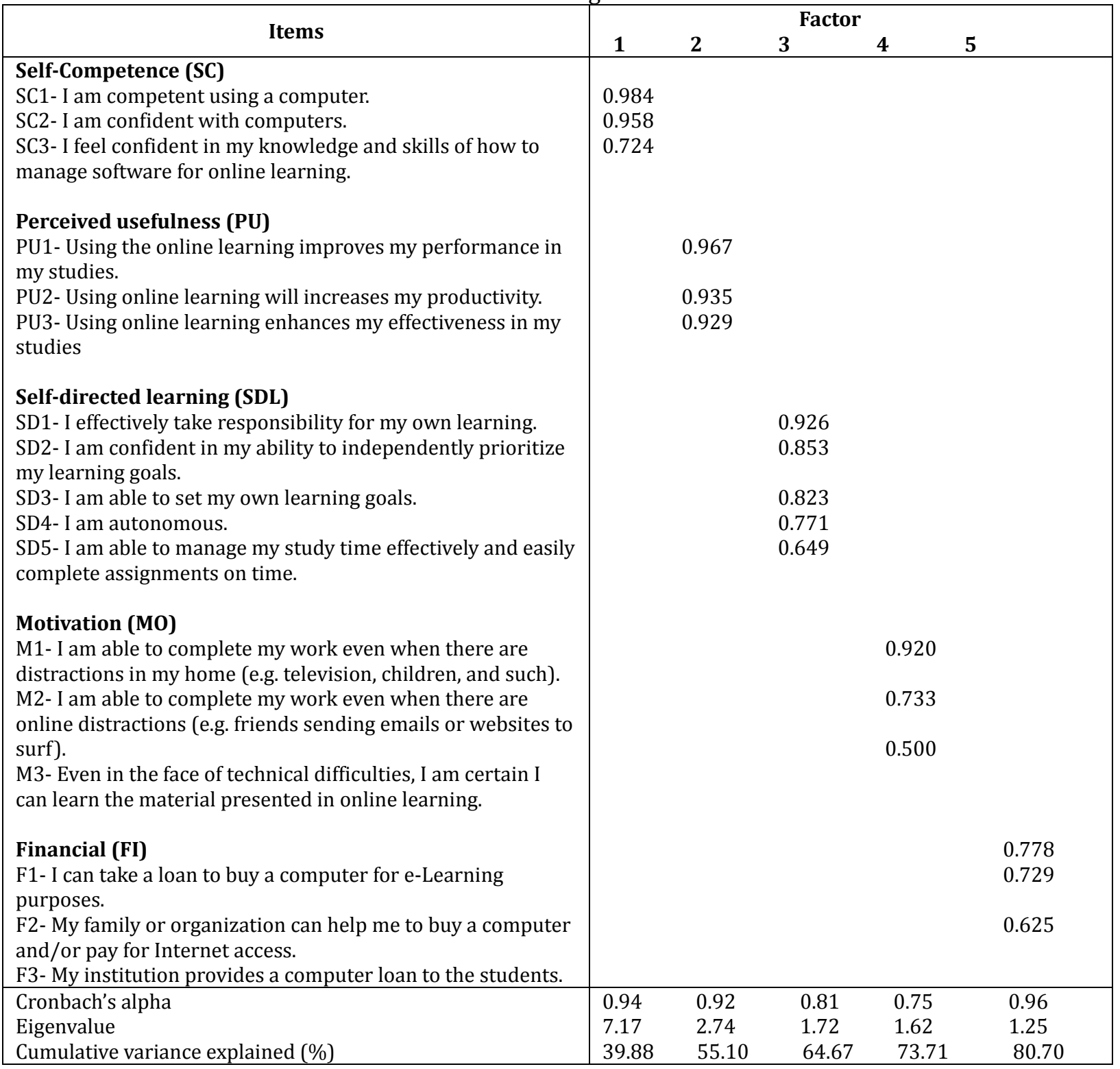

\subsection{Final Test}

Furthermore, to verify the unidimensionality of each factor, a confirmatory factor analysis is considered necessary to evaluate and refine the measurement scale [26].

In this phase, the data collection process is similar to the phase of the pilot test. In the second survey, we collected 573 responses. We excluded from the study 212 questionnaires because respondents had experience in online learning. So we have a sample of 361 respondents to analyze at this stage and have never taken online courses. The data of this sample were analyzed using the Lisrel 8.8 software for Windows [27]. As the assumption of multivariate normality is not respected and the model variables are measured on a Likert scale seven points, the RML (Robust Maximum Likelihood) method seems the most appropriate in this study [27]. The sample size in this phase is 361 greater than the recommended limits. Reference [25] recommends at least 20 observations per independent variable $(361>17 * 20=170)$. 
The participants were predominantly female (77.6\%) compared to males $(22.4 \%)$. The age groups of participants are: less than 20 years $(n=2), 21-25$ years $(n=51), 26-30$ years $(n=73), 31-35$ years $(n=63)$, 36-40 years $(\mathrm{n}=52)$ and 41 years and older $(\mathrm{n}=120)$. Most of them are married 54.8\% $(\mathrm{n}=198), 17.5 \%(\mathrm{n}=$ 63) were single and $24.1 \%$ of participants did not respond to this question. In addition, the majority of respondents work (54.8\% full-time and 7.5\% part-time), only $13.6 \%$ are unemployed, and $24.1 \%$ refused to answer.

\section{Measurement Model}

According to [2], it is best to test more than one model. Therefore, the study tests four models for dimensionality, convergent and discriminant validity of the construct as shown in Fig. 1. The model M1 hypothesizes that a unidimensional first-order factor accounts for the variance among all 17 measurement items. The second model M2 of the first order tests the validity of the five factors with no correlation between them. The third model M3 hypothesizes that the 17 items form into five freely correlated first-order factors. Finally, the model M4 hypothesizes a second-order factor that accounts for the relationships among the five first-order factors.
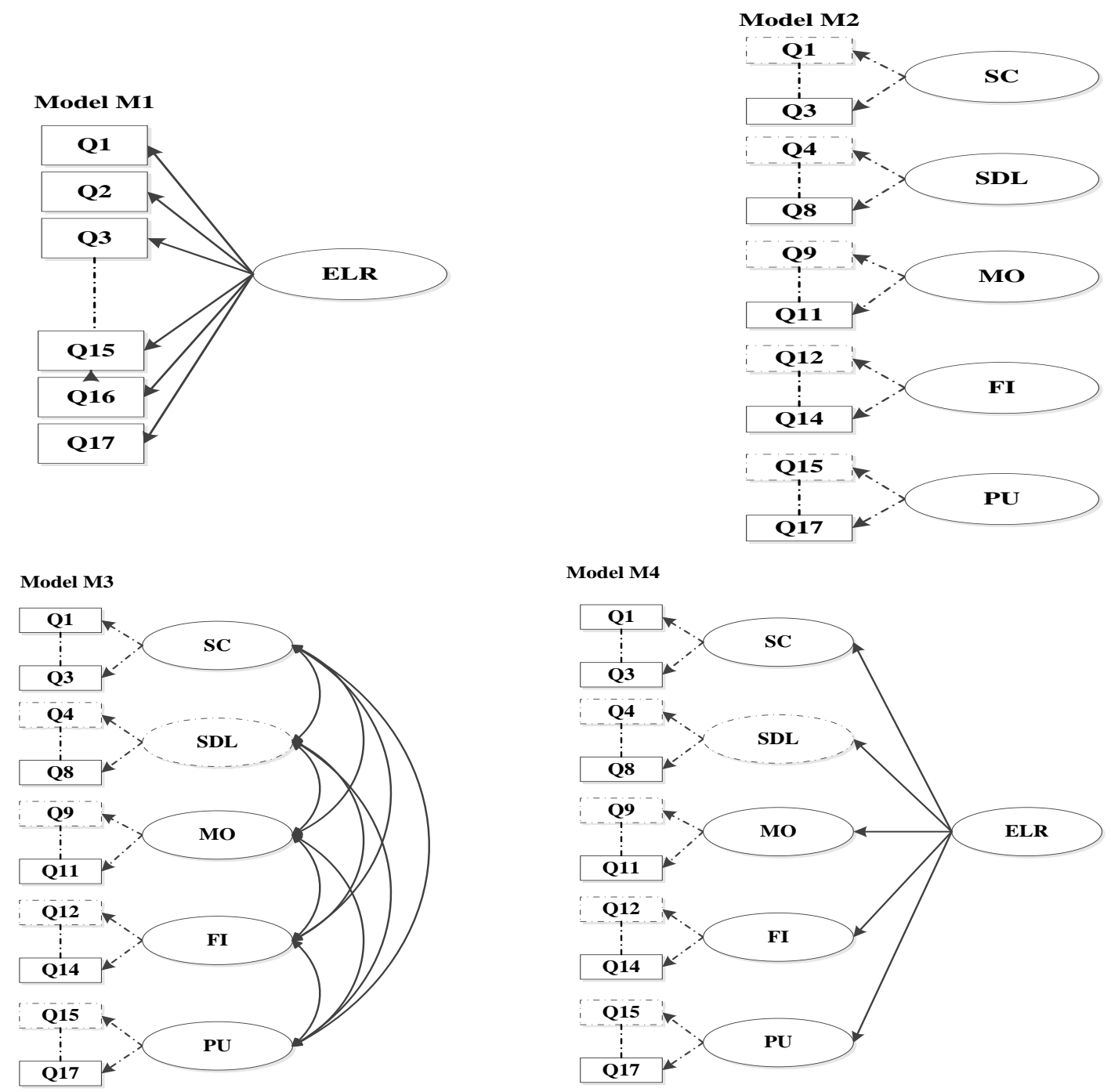

Fig. 1. Alternative models for the ELR scale.

From Table 2, the best fit indices are obtained by the first-order model with 5 interrelated factors (M3) 
compared to M1 and M2 models. The first model M1, which assumes that the instrument is unidimensional (Fig. 1), has a significant value of chi-square $(\chi 2=1642, \mathrm{p}<0.000)$, a ratio $\chi 2 / \mathrm{dl}(12.16)$ greater than 2 , and value of RMSEA (0.176), which is much higher than the recommended standard. These early indications show that perfectly fit the data does not adequately model. Also, the results show that the values of NNFI (0.80), CFI (0.82), GFI (0.55) and AGFI (0.43) are not satisfactory. Finally, the value is greater than the saturated ECVI model, which shows that the model M1 is unstable [28]. Therefore, the results of the first model fit indices show that the dimensional model is inadequate. The model M2 in turn implies that the five dimensions of the model of the first order are not correlated (Fig. 1). The value of $\chi 2$ is significant $(\chi 2=$ 523.72, $\mathrm{p}<0.000$ ), a ratio $\chi 2 / \mathrm{dl}(3.88)$ remains greater than 2 , and the value of RMSEA is beyond the recommended value. Therefore, these results indicate that the data fit within this model. In addition, the model remains unstable because of its ECVI value (1.65) which is greater than the saturated model (0.95). Although this model obtains NNFI and CFI values greater than 0.90, it does not fit. Furthermore, the model M3 presents very satisfactory fit indices as recommended thresholds, as there is no sign of poor fit [28]. The $\chi 2$ value is low compared to other models, the $\chi 2 /$ dll ratio is less than 2 , the index of absolute measuring RMSEA is below 0.5, and other indices (NNFI, CFI, GFI and AGFI) are close to the value 1 . In addition, the expected cross-validation index (ECVI) indicates that this model is stable (ECVI $=0.81<0.85$ saturated model).

Table 2. Model Fit Test Results of Alternatives Models

\begin{tabular}{|c|c|c|c|c|c|c|c|c|c|}
\hline Model & $\chi^{2}$ & dll & $\chi^{2} /$ dll & RMSEA & NNFI & CFI & GFI & AGFI & ECVI \\
\hline M1 & 1642 & 135 & 12.16 & 0.176 & 0.80 & 0.82 & 0.55 & 0.43 & $\begin{array}{c}4.76 \\
(0.95)^{*}\end{array}$ \\
\hline M2 & 523.72 & 135 & 3.88 & 0.089 & 0.95 & 0.95 & 0.81 & 0.76 & $\begin{array}{c}1.65 \\
(0.95)\end{array}$ \\
\hline M3 & 203.96 & 109 & 1.87 & 0.049 & 0.98 & 0.99 & 0.92 & 0.89 & $\begin{array}{c}0.81 \\
(0.85)\end{array}$ \\
\hline M4 & 206.88 & 114 & 1.81 & 0.048 & 0.98 & 0.99 & 0.92 & 0.89 & $\begin{array}{c}0.79 \\
(0.85)\end{array}$ \\
\hline Thresholds & $p \geq 5 \%$ & -- & $\leq 2$ & $\leq 0.05$ & $\begin{array}{r}\geq \\
0.90\end{array}$ & $\geq 0.90$ & $\geq 0.90$ & $\geq 0.80$ & $<$ saturated model \\
\hline
\end{tabular}

$(*)$ : Represents the value of the saturated model.

\section{First-Order vs. Second-Order Factor Models}

The systematic review revealed that the e-learning readiness is multidimensional, although the number of dimensions varies between different tools identified [2]. Furthermore, there is a strong consensus in the field of online education that this concept should be treated as a multidimensional construct. Like the above, we will test the next step if a second order factor explains the covariation links between the first-order factors. The theoretical support has already revealed the existence of the dimensions of this concept ELR.

The second-order approach is used to maximize interpretability both measurement models and structural [25]. Overall, to admit the existence of a second-order model, three conditions must be met [29]: i) quality indices of fit of the factor structure of the second order [30]; ii) the factor contributions of the second order factor to be statistically significant [31]; and iii) the target coefficient $T$ (Target coefficient) [32] should be close to 1 . The target coefficient $\mathrm{T}$ is the ratio of chi-square value of the first-order model with the chi-square value of the second-order model. The value of this coefficient is between 0 and 1 [32].

First, based on the results in Table 2, the fit indices of the model (M4) are considered very acceptable. The $\chi^{2} /$ dll ratio (1.81) is below the recommended threshold. The value of RMESA $(0.048)$ is very satisfactory $[\leq$ 
0.05). The other absolute and incremental indices goodness of fit (NNFI, CFI, GFI and AGFI) are very satisfactory, all are above the required standard. The value of ECVI (0.79) is well below the saturated model (0.85), which is consistent with the standard of acceptability. This indicates that the second-order factor model, which is more restrictive, is a parsimonious model with fewer parameters to estimate, more degrees of freedom, and having almost identical to those first-order indices [30], [31].

Second, Fig. 2 shows that the factor contributions of the second-order factor is above 0.60 except for one dimension (Financial) which is equal to 0.39 but near the threshold required 0.40 [25], [33], [34]. However, [35] points out that a factor weight greater than or equal to 0.38 is considered significant, so we consider that all contributions are acceptable. In addition, all these contributions are statistically significant with $t$ values ranging from 4.92 to 9.80 . Finally, the target coefficient $\mathrm{T}$ which is equal to 0.99 ( $\mathrm{T}=\chi 2$ (M3) / $\chi 2$ (M4) = $203.96 / 206.88$ ), indicates that the second-order factor explained $99 \%$ of the covariation between factors of the first-order, which implies that the relationships among the first-order factors are sufficiently captured by second-order factor [32].

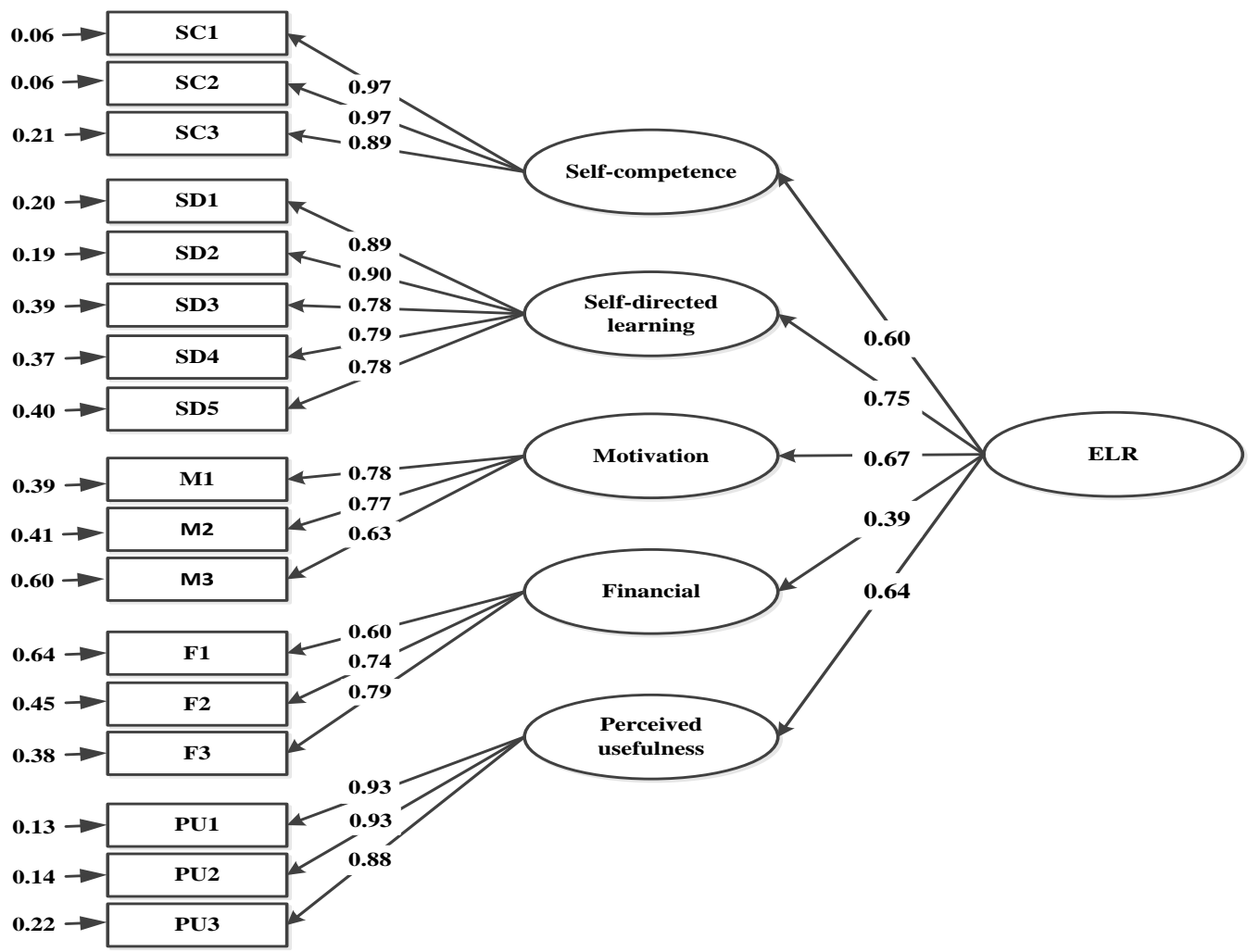

Fig. 2. Second-order model with standardized solution.

Collectively, these results confirm that ELR (e-learning readiness) is a construct of the second-order. In addition, a higher-order model is preferred to the first-order model if the fit of higher-order model is not worse than its first-order model, because it provides a more parsimonious solution [32].

\section{Assessment of Reliability, Convergent and Discriminant Validity}

The composite reliability is used to estimate the reliability of an instrument with the Jöreskog's rho coefficient. From Table 3, all coefficients (Cronbach's alpha and Joreskog's rho) were well above 0.70, indicating that the measurement model scales have adequate and reliable internal consistency [25], [36].

Convergent validity was tested by the method of [36]. This method is to check whether the average variance extracted (AVE) is greater than 0.5 , which means that the variance captured by the corresponding 
construct is more than the measurement error. Table 3 shows that all AVE values are above 0.5, this indicates that the factors have good convergent validity. Also, as we have noted above, that all $t$ values are significant (greater than 1.96), then these results show direct evidence of convergent validity of the ELR measure [36]. Discriminant validity is defined as a degree to which measures of distinct concepts differ [37]. The discriminant validity of the five dimensional scales was tested in two ways. The first, according to [36], a construct has discriminant validity if the AVE value of a construct is greater than any squared inter-correlation of that construct with another. Table 4 displays the square roots of the AVE values, represented in bold on the diagonal of the correlation matrix, are greater than the values below the diagonal.

Thus, discriminant validity is supported for all constructs.

Table 3. Assessment of the Reliability and Validity of the Overall Measurement Model

\begin{tabular}{|c|c|c|c|}
\hline Indicateurs & Alpha & Rhô & AVE \\
\hline \multicolumn{4}{|l|}{ SC1 } \\
\hline SC2 & 0.96 & 0.96 & 0.89 \\
\hline \multicolumn{4}{|l|}{ SC3 } \\
\hline \multicolumn{4}{|l|}{ SDL1 } \\
\hline \multicolumn{4}{|l|}{ SDL2 } \\
\hline SDL3 & 0.91 & 0.92 & 0.70 \\
\hline \multicolumn{4}{|l|}{ SDL4 } \\
\hline \multicolumn{4}{|l|}{ SDL5 } \\
\hline \multicolumn{4}{|l|}{ M01 } \\
\hline MO2 & 0.76 & 0.77 & 0.53 \\
\hline \multicolumn{4}{|l|}{ MO3 } \\
\hline \multicolumn{4}{|l|}{ FI1 } \\
\hline \multirow{2}{*}{\multicolumn{4}{|c|}{$\begin{array}{l}\text { FI2 } \\
\text { FI3 }\end{array}$}} \\
\hline & & & \\
\hline \multicolumn{4}{|l|}{ PU1 } \\
\hline PU2 & 0.94 & 0.94 & 0.84 \\
\hline \multicolumn{4}{|l|}{ PU3 } \\
\hline Thresholds & $\geq 0.70$ & $\geq 0.70$ & $\geq 0.50$ \\
\hline
\end{tabular}

Table 4. Assessment of Discriminant Validity for Five-Factor Model

\begin{tabular}{lccccc}
\hline & SC & SDL & MO & FI & PU \\
\hline SC & $\mathbf{0 . 9 4}$ & & & & \\
SDL & 0.46 & $\mathbf{0 . 8 4}$ & & & \\
MO & 0.39 & 0.52 & $\mathbf{0 . 7 3}$ & $\mathbf{0 . 7 1}$ & \\
FI & 0.26 & 0.24 & 0.25 & 0.31 & $\mathbf{0 . 9 2}$ \\
\hline PU & 0.37 & 0.47 & 0.42 & \\
\hline
\end{tabular}

Second, the discriminant validity could be tested using the method of [37] which consists in comparing the chi-square free model (where the correlations between the latent variables are free) with the constrained model (where the correlations between the latent variables are set to 1). As emphasized [28], the difference between two chi-square distributions follows is itself a chi-square distribution with degrees of freedom equal to the difference of the degrees of freedom of the two models tested, and can therefore be tested statistically.

Thus, as shown in Table 5, the results of this comparison showed that the difference in chi-square (2063.91) between the two models is statistically significant with $\mathrm{p}<0.001$, and indicates that free or unconstrained model clearly has a better fit to the data compared to the constrained model where all correlations between constructs are set to 1. Overall, the discriminant validity is checked with this method.

Globally, these results provided evidence of reliability and validity for the five dimensions of the 
e-learning readiness scale.

Table 5. Assessment of Discriminant Validity by the Chi-Square Test

\begin{tabular}{lccc}
\hline Models & $\chi^{2}$ & ddl & P \\
\hline Free model & 285.79 & 189 & 0.00 \\
Constraint model & 2349.70 & 210 & 0.00 \\
Difference & 2063.91 & 21 & 0.00 \\
\hline
\end{tabular}

\section{Assessment of Predictive Validity}

According to [21], the predictive validity was considered to be part of construct validity. This validity is defined as the ability of the scale to estimate an outcome variable that is external to the measurement instrument itself [25]. Thus, we want to test whether the ELR instrument is able to predict the success (ready) or failure (not ready) of a student before taking online courses.

To this effect, we have constituted two students group: one included those who have successfully completed the online course, and the other included those who have failed. To do this, the two groups were formed on the basis of the sample of the final test $(n=361)$. The first group called "Success" includes students who have received a grade of $\mathrm{D}$ to $\mathrm{A}+$, and the group "Failed" those withdrew from the class with a grade of "AR" or "AX" (AR: withdrawn without academic penalty, AX: withdrawn with academic penalty) or completed it with a grade of $\mathrm{E}$ (failure). The student ranking criterion in both groups was almost similar to that of [12]. The independent variables are the five dimensions of ELR, and we created a dichotomous variable (Group) which takes the value " 0 " if the student has failed and "1" in the case, this variable represents the dependent variable model.

The binary logistic regression is applied to predict whether a student is ready or not to take online classes. This statistic has been widely used in the educational research. According to the results from the analysis of logistic regression, the Hosmer-Lemeshow test is not significant $(\chi 2=11.662$, Sig $=.167)$, this allows to conclude that the model adequately fits the data [25]. The model was able to overall correctly classified $92.2 \%$ of subjects, where $99.1 \%$ of the successful students are classified correctly, but only correctly classifying $7.4 \%$ of non-successful cases. Thus, the model retains predictive power of the order of $92.2 \%$.

The final equation for the binary logistic regression obtained is as follow:

$$
P(y)=\frac{1}{1+e^{-(2.816+0.547 S C+0.291 S D L+0.401 M O-0.440 F I+0.208 P U)}}
$$

$P(y)$ represents the probability that y event happens, and all variables contributed significantly to the predictive ability of the equation, and the major dimensions influencing whether a student is successful (ready) in online learning are self-competence, motivation, and financial. In this case, the prediction of student success in online learning is determined when the probability is higher than 0.5 . Thus, these results confirm that the ELR instrument has satisfactory predictive validity.

\section{Discussion}

The main contribution of this study was the successful development of a valid and reliable test instrument to assess e-learning readiness. The results show that all the items of the instrument ELR are appropriate to help students to evaluate their readiness for online learning. The results of this study indicate that the instrument ELR has high levels of reliability and validity. In terms of reliability, it was 
shown that the ELR tool has internal consistency values (Cronbach's alpha and Jöreskog's rho) very high compared to the ten tools identified in the systematic review conducted by [2]. The internal consistency of these old tools is assessed only by Cronbach's alpha, which is very sensitive to the number of items used [21], while some authors recommend the use of Jöreskog's rho coefficient instead alpha to assess the reliability of a measuring instrument [38].

Regarding the validity of the ELR, the results are also very encouraging. Initially, confirmatory analysis confirms a structure of five dimensions comprising 17 items. The ELR is indeed a suitable instrument for measuring the e-learning readiness taking into account two new dimensions (Financial and perceived usefulness) that were not included in the old instruments. In addition, a confirmatory factor analysis has shown for the first time that ERL is a second-order construct composed of five dimensions, and the results show that ELR construct explains about $99 \%$ of the covariation between the first-order factors (self-competence, self-directed learning, motivation, financial, and perceived usefulness). These first-order factors are largely captured by the second-order factor ELR [32]. The use of a second order factor in our study was to maximize the measurement models and structural interpretability [25], and to enhance the conceptualization of the construct. The systematic review conducted by [2] shows that model with second order factors were neglected in the context of online education.

The current paper provides evidence regarding the predictive validity of the ELR, moreover the results of this research indicate that the ELR instrument is able to correctly distinguish the successful online learners from others in a proportion of $92 \%$. Also, this study shows that the predictive validity of the ELR tool is clearly superior to those tools as [39] with $83 \%$, [34] with $67 \%$ and [12] with $79.3 \%$.

\section{Conclusion}

The results of this study indicate that the ELR (e-learning readiness) is a valid and reliable instrument that could be used in assessing students taking online courses. ELR is best conceptualized as five distinct dimensions: self-competence, self-directed learning, motivation, financial, and perceived usefulness. The instrument validation is the most important step in order to ensure the generation of scientifically valid knowledge. Several authors acknowledge there are still many gaps in knowledge and research in online education [40]. The main objective of this study is to address the shortcomings of existing scales by developing a new reliable and valid standardized tool. The results of systematic review and theories of distance education, have allowed us to build a conceptual framework identifying the e-learning readiness dimensions. The development of a valid and reliable measurement instrument is a long process punctuated by key steps as content validity, pre-test, pilot test (exploratory analysis), and final test (confirmatory analysis). The results obtained, after this long process, show that the ELR instrument consisted of 17 items divided into five dimensions has a good reliability and validity.

This study is unique in the sense it uses structural equation modeling to develop a scale for measuring ELR.

\subsection{Theoretical and Managerial Implications}

On the theoretical side, the tool developed in this study provides researchers a new perspective for the study of phenomenon of student success and retention in the online learning environment. In fact, e-learning readiness is essential for students to be involved in such an environment. The main contribution of our research seems to be the specification of ELR as second-order construct of five first-order dimensions, and it is possible to integrate this concept to the online education theory. This study has conceptually defined what is e-learning readiness construct (ELR), operationally designed this construct into distinct measurable items, and empirically validated the ELR instrument.

On the managerial level, this study shows the importance of assessing the level of preparedness of a 
student towards online learning. Some educational implications are derived from the findings of this study. First, it is expected that administrators or teachers of the universities or colleges may now be able to use this instrument to identify students able to take online courses. The students who are not ready, we suggest, for example, that the university offer a free online course to reduce the dropout and failure rate, and to encourage them to pursue online courses. The ELR instrument developed in this study, when applied in the context of the retention policy has the potential to contribute to reducing the dropout rate of students in the online learning environment. However, most students who wish to take online courses are not prepared, and as a result, there is a higher failure rate. Second, the ELR instrument is not only reliable and valid, but also parsimonious which helps academicians and practitioners to measuring the student's levels of readiness. Third, the multidimensional aspect of the ELR measure can help practitioners better understand what aspects contribute to the student's readiness. The multidimensional aspect of ELR could be useful in practice because it may assist administrators in focusing their interventions. For example, whether the students lack motivation or self-competence, the administrators can make decisions to help them succeed in online learning.

\subsection{Limitations and Recommendations for Future Research}

Moreover, like any measuring instrument, the tool that we propose has a number of limitations. First, note that the ELR instrument has been validated only with students of the university of Quebec (Canada). Second, all samples were composed of graduate and undergraduate students who enrolled in online courses covering multiple disciplines, thus differences in materials and instructors may distort findings. These limitations restrict the generalizability of the study findings, although the resulting instrument has been rigorously validated. However, additional research should validate the ELR instrument by considering different cultures and countries. Further research should be to explore the impact of ELR construct on student performance and satisfaction. In addition, future studies will also need to investigate test-retest reliability in order to examine the stability of the construct over time.

\section{References}

[1] Watkins, R., Leigh, D., \& Triner D. (2004). Assessing readiness for e-learning. Performance Improvement Quarterly, 17(4), 66-79.

[2] Alem, F., Plaisent, M., Bernard, P, \& Chitu, O. (2014). Student online readiness assessment tools: A systematic review approach. Electronic Journal of e-Learning, 12(4), 376-384.

[3] Brown, C. (2002). G-8 collaborative initiatives and the digital divide: Readiness for e-government. Proceedings of 35th Hawaii International Conference on System Sciences (pp. 129-139).

[4] Conley, D. T. (2007). Toward a more comprehensive conception of college readiness. Eugene, OR: Educational

[5] Morris, L., Wu, S., \& Finnegan, C. (2005). Predicting retention in online general education courses. The American Journal of Distance Education, 19(1), 23-36.

[6] Compeau, D. R., \& Higgins, C. A. (1995). Computer self-efficacy: Development of a measure and initial test. MIS Quarterly, 19(2), 189-211.

[7] Chyung, S. Y. (2007). Age and gender differences in online behavior, self-efficacy, and academic performance. Quarterly Review of Distance Education, 8(3), 213-222.

[8] Moore, M., \& Kearsley, G. (2005). Distance Education: A Systems View (2nd ed.). Belmont, CA: Thomson Wadsworth.

[9] Lynch, R., \& Dembo, M. (2004). The relationship between self-regulation and online learning in a blended learning context. International Review of Research in Open and Distance Learning, 5(2), 1-16.

[10] Ryan, R. M., \& Deci, E. L. (2000). Intrinsic and extrinsic motivations: classic definitions and new 
directions. Contemporary Educational Psychology, 25(1), 54-67.

[11] Bolliger, D. U, Supanakorn, S., \& Boggs, C. (2010). Impact of podcasting on student motivation in the online learning environment. Computers \& Education, 55, 714-722.

[12] Roblyer, M. D., Davis, L., Mills, S. C., Marshall, J., \& Pape, L. (2008). Toward practical procedures for predicting and promoting success in virtual school students. The American Journal of Distance Education, 22, 90-109.

[13] Tello, S. (2004). Instructional interaction: Key to student persistence? Distance Education Report, 8(12), 11-3.

[14] Davis, F. D., Bagozzi, R. P., \& Warshaw, P. R. (1989). User acceptance of computer technology: A comparison of two theoretical models. Management Science, 35(8), 982-1003.

[15] Lin, C.-H., Shih, H.-Y., \& Sher, P. J. (2007). Integrating technology readiness into technology acceptance: The TRAM model. Psychology \& Marketing, 24, 641-657.

[16] Boudreau, M. C, Ariyachandra, T., Gefen, D., \& Straub, D. W. (2004). Validating IS positivist instrumentation: 1997-2001. In M.E. Whitman, \& A.B. Woszczynski (Eds), The Handbook of Information Systems Research, Hershey, PA USA, 15-26.

[17] Iwata, J., \& Clayton, J. (2008). Using a perceptual measure to evaluate students' acceptance of digitally-created English learning content.

[18] Fisher, M. J., \& King, J. (2010). The self-directed learning readiness scale for nursing education revisited: A confirmatory factor analysis. Nurse Education Today, 30, 44-48.

[19] Hung, M., Chou, C., Chen, C., \& Own, Z. (2010). Learner readiness for online learning: Scale development and student perceptions, Computers and Education, 55(3), 1080-1090.

[20] McVay, M. (2000). Developing a Web-based distance student orientation to enhance student success in an online bachelor's degree completion program. Nova Southeastern University, Florida.

[21] Cronbach, L. J. (1971). Test validation. In R. L. Thorndike (Ed.), Educational Measurement (2 ${ }^{\text {nd }}$ ed.). Washington, DC: American Council on Education, 443-507.

[22] Fowles, J. (1978). Handbook of Futures Research. Greenwood Press, London.

[23] Lawshe, C. H. (1975). A quantitative approach to content validity. Personnel Psychology, 28, 563-575.

[24] Evrard, Y., Pras, B., \& Roux, E. (2003). Market, Etudes et Recherches en Marketing. Dunod, Paris.

[25] Hair, J., Black, W., Babin, B., Anderson, R., \& Tatham, R. (2006). Multivariate Data Analysis (6th ed.). Pearson Prentice Hall, Upper Saddle River, New Jersey.

[26] Gerbing. D. W., \& Anderson, J. C. (1988). An updated paradigm for scale development incorporating unidimensionality and its assessment. Journal of Marketing Research, 24, 186-192.

[27] Jöreskog, K. G., \& Sörbom, D. (2006). LISREL 8.80 for Windows [Computer Software]. Lincolnwood, IL: Scientific Software International, Inc.

[28] Byrne, B. (1998). Structural Equation Modeling with LISREL, PRELIS and SIMPLIS. Maywah: Erlbaum.

[29] Tanriverdi, H., \& Uysal, V. B. (2011). Measurement properties of the cross-business IT integration construct. Online Supplement for ISR.

[30] Tippins, M. J., \& Sohi, R. S. (2003). IT competency and firm performance: Is organizational learning a missing link? Strategic Management Journal, 24(8), 745-761.

[31] Venkatraman, N. (1990). Performance implications of strategic coalignment: A methodological perspective. Journal of Management Studies, 27, 19-41.

[32] Marsh, H. W., \& Hocevar, D. (1985). Application of confirmatory factor analysis to the study of self-concept. Psychological Bulletin, 97, 562-582.

[33] Churchill, G. (1979). A paradigm for developing better measures of marketing constructs. Journal of Marketing Research, 16, 64-73. 
[34] Osborn, V. (2001). Identifying at-risk students in videoconferencing and web-based distance education. American Journal of Distance Education, 15(3), 41-54.

[35] Harman, H. (1976). Modern Factor Analysis (3 $3^{\text {rd }}$ ed.). Chicago: University of Chicago Press.

[36] Fornell, C., \& Larcker, D. F. (1981). Evaluating structural equation models with unobservable variables and measurement error. Journal of Marketing Research, 18(1), 39-50.

[37] Bagozzi, R. P., \& Yi, Y. (1991). Multitrait-multimethod matrices in consumer research. Journal of Consumer Research, 17, 426-439

[38] Roussel, P., Durrieu, F., Campoy, E., \& Akremi, A. (2002). Méthodes d'Équations Structurelles: Recherche et Applications en Gestion. Economica.

[39] Muse, H. E. (2003). The web-based community college student: An examination of factors that lead to success and risk. Internet and Higher Education, 6, 241-261.

[40] Gambescia, S. F., \& Paolucci, R. (2009). Academic fidelity and integrity as attributes of university online degree program offerings. Online Journal of Distance Learning Administration, 12(1).

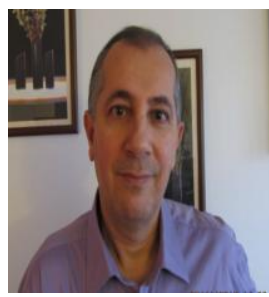

Farid Alem is a professor of information system at Ahuntsic College of Montreal, Canada. He holds a Ph.D in information system from the University of Quebec in Montreal. He received his diploma degree in information technology and master degree in business administration from Moncton University, New Brunswick, Canada. In addition, he is graduated in computer science from the Algiers University, Algeria.

Dr. Alem has taught in higher education for over 10 years as lecturer in many universities, and also has a great experience as computer engineer. His current research interests include e-learning, management information system, cloud computing, and project management.

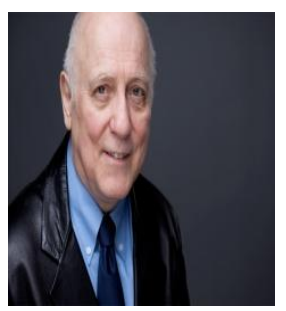

Michel Plaisent is a full professor in the Business School of University of Québec in Montréal. He received a diploma in computer sciences (1971); later on he received a M.Sc. in project management (1980) and a Ph.D. in Information Technology Management (1987) at University of Quebec in Montreal. His doctoral research was pioneer as he studied the use of computer mediated communication systems by CEO.

He joined the University of Québec in Montréal in 1980 where he held different position while developing his research career as professor, namely IT program director for 6 years. His researches continue to focus on human factors of IT, namely cognitive ergonomics, learning problems and personal productivity tools for managers. Among his main research is the use of social media by Canadian charities to create and maintain a community of practice in the philanthropy sector.

Dr. Plaisent has published more than 25 books and more than hundreds of articles in academic journals and international conferences. On International dimension, he is engaged in China MBA program and other Asian universities.

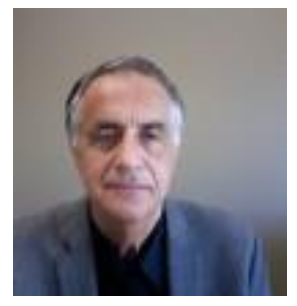

Cataldo Zuccaro obtained a Ph.D. in marketing at the University of Quebec in Montreal in 1999. He is a professor of marketing at the University of Quebec in Montreal. He had been a director of the MBA Research and the chair of the department of business strategies. He is a specialist in data analysis, business analytics and marketing. His areas of research are marketing research methods, business modeling, customer scoring and segmentation, business analytics and research methods.

He has taught and continues to teach in the university's Executive MBA program in such countries as Romania, Poland, France, Morocco, Algeria, Tunisia, Lebanon, Mexico and Peru. He has also consulted for large multinational corporations and government agencies. 
Dr. Zuccaro has published his research in such journals as recherches sociologiques, la revue des sciences administratives du Canada, Journal of the market research society Journal of social psychology, International journal of market research, Journal of modelling management, International journal of bank marketing, Social research indicators and the Journal of Economics and Economic Education Research. Dr. Zuccaro is the winner, in 2010, of the silver medal for the best paper in the International Journal of Market Research.

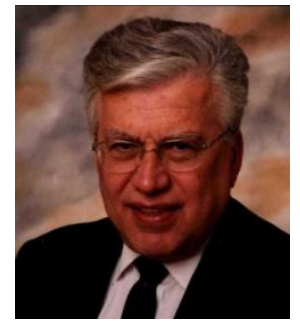

Prosper Bernard has a solid multidisciplinary academic background, with a Ph.D. in Business Administration from the City University of New York and an MBA from St-John's University in New York. He also holds a B.A. from the University of Montreal, Summa Cum Laude, and a B.Sc. from McGill, a CDP in Data processing, a CMC in Management consulting, and an Adm. A. in Management. He has published several books and articles.

He is an internationally respected lecturer and consultant with extensive experience in business strategy, project management, management of information systems, international Bbsiness/marketing, and international business education. He has served as vice-president at the University of Québec at Montreal, Dean of the School of Business, one of the largest in North America, as Director of the Executive MBA program, president of the graduate studies committee, and director of the $\mathrm{PhD}$ program in Business run in a Consortium of the four Montreal Universities. He has lectured and has acted as a visiting professor at many universities, including McGill University, the University of Alberta, St-John's University in New York, Ecole Polytechnique, Barry University in Miami, the University of Southern California, the Fundacão Getulio Vargas, São Paulo, Brazil, The University of Sarasota, INCAE in Costa Rica, the University Claude Bernard in Lyon, France, and many others. He has held managerial positions in Information Systems in the fields of banking, insurance, education, and transportation.

Dr. Bernard has received two medals from the China's government for its contribution to China- Canada friendship and his implication with education. 